UniversitätsSpital Zürich

Institut für Hausarztmedizin

Direktor: Prof. Dr. med. Th. Rosemann, PhD

Arbeit unter Leitung von Dr. med. S. Djalali und

Dr. med. S. Neuner-Jehle MPH

\title{
The impact of an individualized risk-adjusted approach on hypertension treatment in primary care
}

\author{
INAUGURAL-DISSERTATION \\ zur Erlangung der Doktorwürde der Humanmedizin \\ an der Medizinischen Fakultät \\ der Universität Zürich
}

vorgelegt von

Stefan Zechmann

Genehmigt auf Antrag von Prof. Dr. med. Th. Rosemann, PhD

Zürich 6. April 2017 


\section{Publikationshinweis}

The impact of an individualized risk-adjusted approach on hypertension treatment in primary care

Publiziert am: 06. Januar 2017

Journal: The Journal of Clinical Hypertension 2017;00:1-9.

(doi:10.1111/jch.12958), 


\section{Publikation}




\section{The impact of an individualized risk-adjusted approach on hypertension treatment in primary care}

\section{Stefan Zechmann MD ｜ Oliver Senn MD ｜ Fabio Valeri MSc ｜ Stefan Neuner-Jehle MD | Thomas Rosemann MD PhD | Sima Djalali MD the FIRE Study Group}

Institute of Primary Care, University of Zurich, University Hospital Zurich, Zurich, Switzerland

\section{Correspondence}

Stefan Zechmann, MD, Institute for Primary Care and Health Services Research, University of Zurich, Zurich, Switzerland.

Email: stefan.zechmann@usz.ch
Previous studies suggest that up to $60 \%$ of all patients with hypertension receive inappropriate treatment. Current 2013 European Society of Hypertension/European Society of Cardiology (ESH/ESC) guidelines recommend taking cardiovascular risk factors into account when assessing treatment for patients with hypertension. The authors hypothesize that this approach will reduce the proportion of patients receiving inappropriate treatment. In this cross-sectional study using electronic medical records of Swiss primary care patients, the authors estimate the proportion of patients receiving inappropriate treatment using two approaches: (1) based on a blood pressure threshold of 140/90 mm Hg; and (2) based on cardiovascular risk factors. A total of 22434 patients with hypertension were identified. Based on these approaches, $72.7 \%$ and $44.6 \%$ of patients, respectively, qualified for drug treatment. In addition, $23.0 \%$ and $10.8 \%$ of patients, respectively, received inappropriate treatment. Application of the 2013 ESH/ESC guidelines reduced the proportion of patients receiving inappropriate treatment by $50 \%$. This shows the major impact of risk adjustment and highlights the need for a patient-centered approach in hypertension treatment.

\section{1 | INTRODUCTION}

Elevated blood pressure (BP) is a leading risk factor for premature death, stroke, and heart disease worldwide. ${ }^{1-3} \mathrm{~A}$ broad armament of evidence-based treatment options as well as guidelines providing the latest evidence on how to use these different treatment options exist. $^{3-7}$ Nevertheless, there is suspicion that a considerable proportion of patients diagnosed with hypertension worldwide do not receive appropriate treatment. Different studies have found a substantial gap between guideline recommendations and the actual treatment of hypertension in patients. ${ }^{8-15}$ This gap is often referred to as the evidence-performance gap (EPG). ${ }^{16,17}$ Approximately $60 \%$ or more patients with hypertension worldwide, especially patients treated in primary care settings, might be affected by the EPG. These previous studies used the BP threshold of $140 / 90 \mathrm{~mm} \mathrm{Hg}$ as a single criterion for appropriate treatment. Consequently, all patients with a BP $\geq 140 / 90 \mathrm{~mm} \mathrm{Hg}$ without treatment, disregarding their overall cardiovascular risk (CVR), were defined as being affected by the EPG.
Because comorbidities and other CVR factors in addition to hypertension are frequent in real-life patients, especially in the primary care setting, the integration of comorbidities and CVR factors into the assessment is important. ${ }^{18-21}$

Recent studies support the recommendation to shift focus from rigid BP thresholds to patients' overall CVR to facilitate an individualized risk-adjusted assessment whenever deciding on hypertension treatment. A possible explanation for the EPG is that primary care physicians (PCPs) adapt guideline recommendations to the needs of their real-life patients, a finding that has been shown in diabetes management. ${ }^{22}$ Thus, EPGs might rather be explained by an individualized risk-adjusted assessment than by low adherence to guidelines. $^{23}$

The latest guidelines of the European Society of Hypertension (ESH) and the European Society of Cardiology (ESC) published in 2013 recommend a broader and more individualized approach whenever assessing treatment options of patients with hypertension. This new risk-adjusted approach takes other CVR factors, patients' age, and 
frailty into account. At present, the 2013 ESH/ESC guidelines are the clinical standard for the management of patients with hypertension in Europe.

However, the proportion of patients with hypertension who qualify for treatment according to these guidelines remains unknown, as it is true for the proportion of patients affected by the EPG.

We hypothesize that the risk-adjusted approach will result in a smaller proportion of patients who qualify for treatment; thus, the EPG will decrease.

\section{2 | METHODS}

This cross-sectional study used data collected from electronic medical records of primary care patients with hypertension registered between January 2009 and August 2015. We estimated the proportion of patients qualifying for treatment according to two different approaches and assessed whether PCPs had prescribed treatment or not. The primary outcome of the study was the proportion of patients who did not receive treatment although recommended by guidelines. By definition, these patients were considered as being affected by an EPG. The secondary outcome was the difference between the EPG estimations obtained by the two approaches.

First, patients were stratified according to the BP threshold of $140 / 90 \mathrm{~mm} \mathrm{Hg}$, subsequently referred to as "standardized BP approach." Second, patients were stratified to CVR categories according to BP levels and additional CVR factors as recommended in the 2013 ESH/ESC guidelines, subsequently referred to as "risk-adjusted approach." $^{24}$

\section{1 | Data collection}

Medical record data were extracted from the database of the Family Medicine ICPC-Research Using Electronic Medical Records (FIRE) project. FIRE is an ongoing research project of the Institute of Primary Care at the University and University Hospital of Zurich, Switzerland, involving PCPs in the German-speaking part of Switzerland. PCPs voluntarily provide standardized, anonymized medical record data of all patient encounters in daily practice. Data include patients' demographics, vital signs, diagnostic codes using the second version of the International Classification of Primary Care (ICPC-2), ${ }^{25,26}$ laboratory values, and data on medication using the Anatomical Therapeutic Chemical Classification System (ATC). ${ }^{27}$ Further details on the FIRE database and its validation are provided elsewhere. $^{21,28}$

\section{2 | Patients}

All patients registered in the FIRE database between January 2009 and August 2015 were assessed for the eligibility criterion hypertension.

The definition of hypertension was based on the occurrence of at least one of the following criteria (which were searched for in the following hierarchically order):
- more than two BP measurements $\geq 140 / 90 \mathrm{~mm} \mathrm{Hg}$ or

- at least one recorded ICPC-2 coding (K85 "elevated blood pressure," K86 "hypertension uncomplicated," K87 "hypertension complicated") or

- at least two prescriptions for antihypertensive drugs according to ATC coding as validated by Lamers and colleagues ${ }^{29}$ ( $\mathrm{CO} 2$ "antihypertensives," C03A "low-ceiling diuretics, thiazides," C03EA01 "hydrochlorothiazide and potassium-sparing agents," C07 "beta-blocking agents," C08 "calcium channel blockers," C09A "ACE inhibitors, plain," C09B "ACE inhibitors, combinations") and ATC coding of angiotensin II receptor antagonists (C09C "angiotensinogen II antagonists, plain," C09D "angiotensinogen II antagonists, combinations").

Patients who had fewer than two BP measurements (regardless of the measured value [this was possible as eligible patients had to meet only one and not all three inclusion criteria to be eligible]), fewer than two PCP consultations, were younger than 18 years, or pregnant were excluded.

Patients' individual observation period was defined using an inclusion and an end date. The first visit date on which a patient met one of the three inclusion criteria was used as the inclusion date. The end date was the date of the latest visit a BP measurement was made. ICPC-2 codes were used if they occurred only once, as these codes were based on best medical practice by participating PCPs who did the coding by themselves. ATC codes were used if they occurred at least twice to avoid prescription errors. We used the latest available data for changing parameters (eg, laboratory data or demographic data such as weight) going backward starting at the end date.

\section{3 | Baseline characteristics}

The following baseline characteristics of included patients were assessed based on medical record entries: "age," "antihypertensive drugs," "concomitant nonantihypertensive drugs," "concomitant chronic diseases," "BP measurements," "risk factors," and "asymptomatic organ damage." Patients' chronic comorbidities were assessed based on the ICPC-2 classification as recommended by O'Halloran and colleages $^{30}$ and based on PCGs. ${ }^{29}$

\subsection{Stratification according to BP levels (standardized BP approach)}

We established five hypertension grade groups: normal (systolic BP [SBP] $\leq 129 \mathrm{~mm} \mathrm{Hg}$ and diastolic BP [DBP] $\leq 84 \mathrm{~mm} \mathrm{Hg}$ ), high normal (SBP 130-139 mm Hg, DBP 85-89 mm Hg), grade 1 (SBP 140159 mm Hg, DBP 90-99 mm Hg), grade 2 (SBP 160-179 mm Hg, DBP 100-109 mm Hg), and grade $3\left(\mathrm{SBP} \geq 180 \mathrm{~mm} \mathrm{Hg}, \mathrm{DBP} \geq 110 \mathrm{~mm} \mathrm{Hg}\right.$ ). ${ }^{24}$

Patients were stratified to these groups based on the mean value of all recorded BP measurements. As recommended by the 2013 ESC/ ESH guidelines, stratification to a specific hypertension grade group was based on the higher level, regardless of whether it was SBP or DBP. If two BP measurements were available from the same visit, we used the mean of the two available values. 


\begin{tabular}{|c|c|c|c|c|c|}
\hline \multirow{2}{*}{$\begin{array}{l}\text { Other RFs, } \\
\text { asymptomatic } \\
\text { or disease }\end{array}$} & \multicolumn{5}{|c|}{ Blood Pressure, $\mathrm{mm} \mathrm{Hg}$} \\
\hline & $\begin{array}{c}\text { Normal } \\
\text { SBP } \leq 129 \\
\text { or DBP } \leq 84\end{array}$ & $\begin{array}{l}\text { High normal } \\
\text { SBP } 130-139 \\
\text { or DBP } 85-89\end{array}$ & $\begin{array}{l}\text { Grade I HT } \\
\text { SBP 140-159 } \\
\text { or DBP 90-99 }\end{array}$ & $\begin{array}{c}\text { Grade II HT } \\
\text { SBP 160-179 } \\
\text { or DBP 100-109 }\end{array}$ & $\begin{array}{l}\text { Grade III HT } \\
\text { SBP } \geq 180 \\
\text { or DBP } \geq 110\end{array}$ \\
\hline No other RF & $\begin{array}{l}\cdot \text { No BP intervention } \\
n=116\end{array}$ & $\begin{array}{l}- \text { No BP intervention } \\
n=423\end{array}$ & $\begin{array}{l}\text { Lifestyle changes } \\
\text { for several months } \\
\text { Then add BP drugs } \\
\text { targeting }<140 / 90 \\
n=1265\end{array}$ & $\begin{array}{l}- \text { Lifestyle changes } \\
\text { for several weeks } \\
- \text { Then add BP } \\
\text { drugs } \\
\text { targeting }<140 / 90 \\
n=308\end{array}$ & $\begin{array}{l}\cdot \text { Lifestyle changes } \\
\text { - Immediate BP } \\
\text { drugs } \\
\text { targeting }<140 / 90 \\
n=44\end{array}$ \\
\hline 1-2 RF & $\begin{array}{l}\text { - No BP intervention } \\
n=900\end{array}$ & $\begin{array}{l}\text { - Lifestyle changes } \\
\text { - No BP } \\
\text { Intervention } \\
n=1224\end{array}$ & $\begin{array}{l}- \text { Lifestyle changes } \\
\text { for several weeks } \\
\text { - Then add BP } \\
\text { drugs } \\
\text { targeting }<140 / 90 \\
n=3554\end{array}$ & $\begin{array}{l}- \text { Lifestyle changes } \\
\text { for several weeks } \\
\text { - Then add BP } \\
\text { drugs } \\
\text { targeting }<140 / 90 \\
n=845\end{array}$ & $\begin{array}{l}\cdot \text { Lifestyle changes } \\
\cdot \text { Immediate BP } \\
\text { drugs } \\
\text { targeting }<140 / 90 \\
n=141\end{array}$ \\
\hline$\geq 3 \mathrm{RF}$ & $\begin{array}{l}\cdot \text { No BP intervention } \\
n=208\end{array}$ & $\begin{array}{l}\text { - Lifestyle changes } \\
\text { - No BP } \\
\text { Intervention } \\
n=147\end{array}$ & $\begin{array}{l}\text { - Lifestyle changes } \\
\text { for several weeks } \\
\text { - Then add BP } \\
\text { drugs } \\
\text { targeting }<140 / 90 \\
n=325\end{array}$ & $\begin{array}{l}\text { - Lifestyle changes } \\
\text { - BP drugs } \\
\text { targeting }<140 / 90 \\
n=247\end{array}$ & $\begin{array}{l}\cdot \text { Lifestyle changes } \\
\text { - Immediate BP } \\
\text { drugs } \\
\text { targeting }<140 / 90 \\
n=22\end{array}$ \\
\hline $\begin{array}{l}\text { OD, CKD stage } 3 \text {, } \\
\text { or diabetes }\end{array}$ & $\begin{array}{l}- \text { No BP intervention } \\
n=0\end{array}$ & $\begin{array}{l}\text { - Lifestyle changes } \\
\text { - No BP } \\
\text { Intervention } \\
n=2626\end{array}$ & $\begin{array}{l}\text { - Lifestyle changes } \\
\text { - BP drugs } \\
\text { targeting }<140 / 90 \\
n=6467\end{array}$ & $\begin{array}{l}\text { - Lifestyle changes } \\
\text { - BP drugs } \\
\text { targeting < 140/90 } \\
n=1484\end{array}$ & $\begin{array}{l}- \text { Lifestyle changes } \\
\text { - Immediate BP } \\
\text { drugs } \\
\text { targeting }<140 / 90 \\
\mathrm{n}=272\end{array}$ \\
\hline $\begin{array}{l}\text { Symptomatic CVD, } \\
\text { CKD stage } \geq 4 \text {, or } \\
\text { diabetes with } \\
\text { OD/RFs }\end{array}$ & $\begin{array}{l}- \text { No BP intervention } \\
n=0\end{array}$ & $\begin{array}{l}\text { - Lifestyle changes } \\
\text { - No BP } \\
\text { Intervention } \\
n=480\end{array}$ & $\begin{array}{l}\text { - Lifestyle changes } \\
\text { - BP drugs } \\
\text { targeting <140/90 } \\
n=1061\end{array}$ & $\begin{array}{l}\text { - Lifestyle changes } \\
\text { - BP drugs } \\
\text { targeting }<140 / 90 \\
n=234\end{array}$ & $\begin{array}{l}- \text { Lifestyle changes } \\
\text { - Immediate BP } \\
\text { drugs } \\
\text { targeting }<140 / 90 \\
n=41\end{array}$ \\
\hline
\end{tabular}

FIGURE 1 Stratification of patients. BP, blood pressure; DBP, diastolic blood pressure; SBP, systolic blood pressure; HT, hypertension; CKD, chronic kidney disease; CVD, cardiovascular disease; OD, organ damage; RFs, risk factors

\section{5 | Stratification according to CVR categories (risk-adjusted approach)}

As recommended by the 2013 ESH/ESC guidelines, we established eight CVR categories: average, low, low-moderate, moderate, moderate-high, high, high-very high, and very high depending on the patients' hypertension grade group and number of existing risk factors, asymptomatic organ damage, and established diseases (see Figure 1 for details). Therefore, we searched each patient's latest medical record for ICPC-2 diagnoses, medication lists/ATC codes, and laboratory results (Table 1 ).

\section{6 | Treatment criteria}

All patients stratified to hypertension grade $\geq 1$ group qualified for drug treatment according to the standardized BP approach.

All patients with hypertension grade $\geq 1$ group with a CVR category of at least "high" qualified for drug treatment according to the risk-adjusted approach.

Exceptions within the risk-adjusted approach apply to young patients with isolated systolic hypertension (ISH) and elderly patients. In the context of ISH, patients 30 years or younger were determined as "young."
We therefore decided to consider patients 30 years and younger with a mean SBP level of $>140 \mathrm{~mm} \mathrm{Hg}$ and a mean DBP level of $<90 \mathrm{~mm} \mathrm{Hg}$ as patients affected by ISH. In regard to age, neither the $2013 \mathrm{ESH} /$ ESC guideline nor general medical literature defines exact thresholds for "elderly." ${ }^{24,32-35}$ Thus, we did not set an exact age threshold and stratified patients affected by the EPG according to age (Figure 4).

In order to assess possible changes in clinical practice over the observation period of 6 years, we performed a sensitivity analysis comparing patients within the first 3 years with patients within the last 3 years. Because eligible patients could be found anytime between January 1, 2009, and December 31, 2015, and the duration of patients' observation period was subject to change, patients included in the first as well as the last years were not included in this sensitivity analysis.

\section{7 | Statistical analysis}

Continuous variables are presented as means and standard deviations (SDs) and categorical data as frequencies and percentages. We used Walds interval to calculate the confidence interval $(\mathrm{Cl}){ }^{36}$ Data analysis was performed using $\mathrm{R}$ statistics software (version 3.2.0; R Foundation, Vienna, Austria). 
TABLE 1 Definition of risk factors, asymptomatic organ damage, and established disease

\begin{tabular}{|c|c|c|}
\hline Risk factors & Male sex & Male sex \\
\hline & Age & $\begin{array}{l}\text { Male sex and age } \geq 55 \text { y or female sex and age } \geq 65 \text { y (age assessed on date of } \\
\text { study inclusion) }\end{array}$ \\
\hline & Dyslipidemia & $\begin{array}{l}\text { Use of lipid-lowering-medication (ATC C10) or ICPC- } 2 \text { code (lipid disorder) or } \\
\text { cholesterin }>4.9 \mathrm{mmol} / \mathrm{L} \text { or low-density lipoprotein }>3.0 \mathrm{mmol} / \mathrm{L} \text { or } \\
\text { triglycerides }>1.7 \mathrm{mmol} / \mathrm{L} \text {, or male sex and high-density lipoprotein } \\
<1.0 \mathrm{mmol} / \mathrm{L} \text { or female sex and high-density lipoprotein }<1.2 \mathrm{mmol} / \mathrm{L}\end{array}$ \\
\hline & Obesity & ICPC -2 code (obesity) or $\mathrm{BMI} \geq 30$ \\
\hline & Elevated fasting glucose & Fasting glucose level between $5.6 \mathrm{mmol} / \mathrm{L}$ and $6.9 \mathrm{mmol} / \mathrm{L}$ \\
\hline \multirow[t]{2}{*}{ Asymptomatic organ damage } & Pulse pressure & $\begin{array}{l}\text { Difference between systolic and diastolic blood pressure } \geq 60 \mathrm{~mm} \mathrm{Hg} \text { and age } \\
\geq 65 \text { y (age assessed on date of study inclusion) }\end{array}$ \\
\hline & Chronic kidney disease Grade 3 & $\begin{array}{l}\text { Glomerular filtration rate between } 30 \mathrm{~mL} / \mathrm{min} / 1.73 \mathrm{~m}^{2} \text { and } 60 \mathrm{~mL} / \mathrm{min} / 1.73 \mathrm{~m}^{2} \\
\text { according to CKD-EPI formula }{ }^{\text {a }}\end{array}$ \\
\hline \multirow[t]{3}{*}{ Established disease } & Chronic kidney disease Grade 4 & $\begin{array}{l}\text { Glomerular filtration rate }<30 \mathrm{~mL} / \mathrm{min} / 1.73 \mathrm{~m}^{2} \text { according to CKD-EPI } \\
\text { formula }^{a}\end{array}$ \\
\hline & Diabetes & $\begin{array}{l}\text { Use of antidiabetic medication (ATC A10A, A10B, A10X) or ICPC- } 2 \\
\text { code (diabetes insulin dependent, diabetes not insulin dependent) or at } \\
\text { least two fasting blood sugar measurements } \geq 7.0 \mathrm{mmol} / \mathrm{L} \text { or glycated } \\
\text { hemoglobin } \geq 6.5 \%\end{array}$ \\
\hline & Cardiovascluar disease & $\begin{array}{l}\text { Use of cardiac medication (ATC CO1) or ICPC-2 code (ischemic heart disease } \\
\text { with angina, acute myocardial infarction, ischemic heart disease with/without } \\
\text { angina, heart failure, atrial fibrillation/flutter, paroxysmal tachycardia, } \\
\text { transient cerebral ischemia, stroke/cerebrovascular accident, cerebrovascular } \\
\text { disease, arteriosclerosis/PVD, retinopathy) }\end{array}$ \\
\hline
\end{tabular}

${ }^{a}$ Chronic Kidney Disease Epidemiology collaboration equation (CKD-EPI): glomerular filtration rate $(\mathrm{GFR})=141 \times \mathrm{min}(\mathrm{Scr} / \mathrm{K}, 1)^{\alpha} \times \max (\mathrm{Scr} / \mathrm{K}$, $1)^{-1.209} \times 0.993^{\text {Age }} \times 1.018$ [if female] $\times 1.159$ [if black]; K=0.7 if female and 0.9 if male; $\alpha=-0.329$ if female and -0.411 if male; min=the minimum of Scr/K or 1 ; max=the maximum of Scr/K or 1; Scr=serum creatinine $(\mathrm{mg} / \mathrm{dL}) .{ }^{28}$ Abbreviations: ATC, Anatomical Therapeutic Chemical Classification System; BMI, body mass index; ICPC-2, second version of the International Classification of Primary Care; PVD, peripheral vascular disease.

\section{3 | RESULTS}

Until August 2015, 264641 primary care patients were registered in the FIRE database. All patients were assessed for the eligibility criterion hypertension and 48602 were defined as eligible. Of these, 20236 patients were excluded because they had fewer than two BP measurements available, 312 patients had fewer than two PCP consultations, 5613 patients were younger than 18 years, and seven patients were pregnant. Data on the remaining 22434 patients with hypertension were included in the analysis (Figure 2).

The average age of included patients was 66.4 years and $50.7 \%$ were male. The average observation period for the individual patient was 2.7 years. During observation, on average 9.7 BP measurements per patient were performed, corresponding to an average of 3.7 BP measurements per patient per year. In addition to hypertension, patients had a mean of 4.8 concomitant chronic diseases and took 5.9 concomitant nonantihypertensive drugs. Detailed baseline characteristics are shown in Table 2.

\section{1 | Standardized BP approach}

Based on the BP threshold of 140/90 mm Hg, 72.7\% (95\% Cl, 72.073.4) of all patients qualified for drug treatment. About $49.7 \%(95 \%$ $\mathrm{Cl}, 48.8-50.1)$ received a drug as recommended, while $23.0 \%(95 \% \mathrm{Cl}$,
21.8-24.1) received no drugs although they qualified for treatment. The latter were therefore identified as being affected by the EPG (Figure 3).

\section{2 | Risk-adjusted approach}

Based on the CVR categories, $44.6 \%(95 \% \mathrm{Cl}, 43.6-45.6)$ of all patients qualified for drug treatment. A total of $33.9 \%(95 \% \mathrm{Cl}$, $32.8-34.9)$ received a drug as recommended, while $10.8 \%(95 \% \mathrm{Cl}$, 9.5-12.0) received no drugs although they qualified for treatment. The latter were therefore identified as being affected by the EPG (Figure 3).

\section{3 | Difference between approaches}

The proportion of patients affected by the EPG differed by $12.2 \%$ (95\% Cl, 10.9-13.4) depending on the approach used.

\subsection{Further analysis}

The stratification of all patients to the eight different CVR categories showed that 53.2\% (11 941/22 434) of all patients were assigned to the moderate-high or to a lower CVR category. Accordingly, $46.8 \%$ (10 493/22 434) were assigned to higher CVR categories, but only 


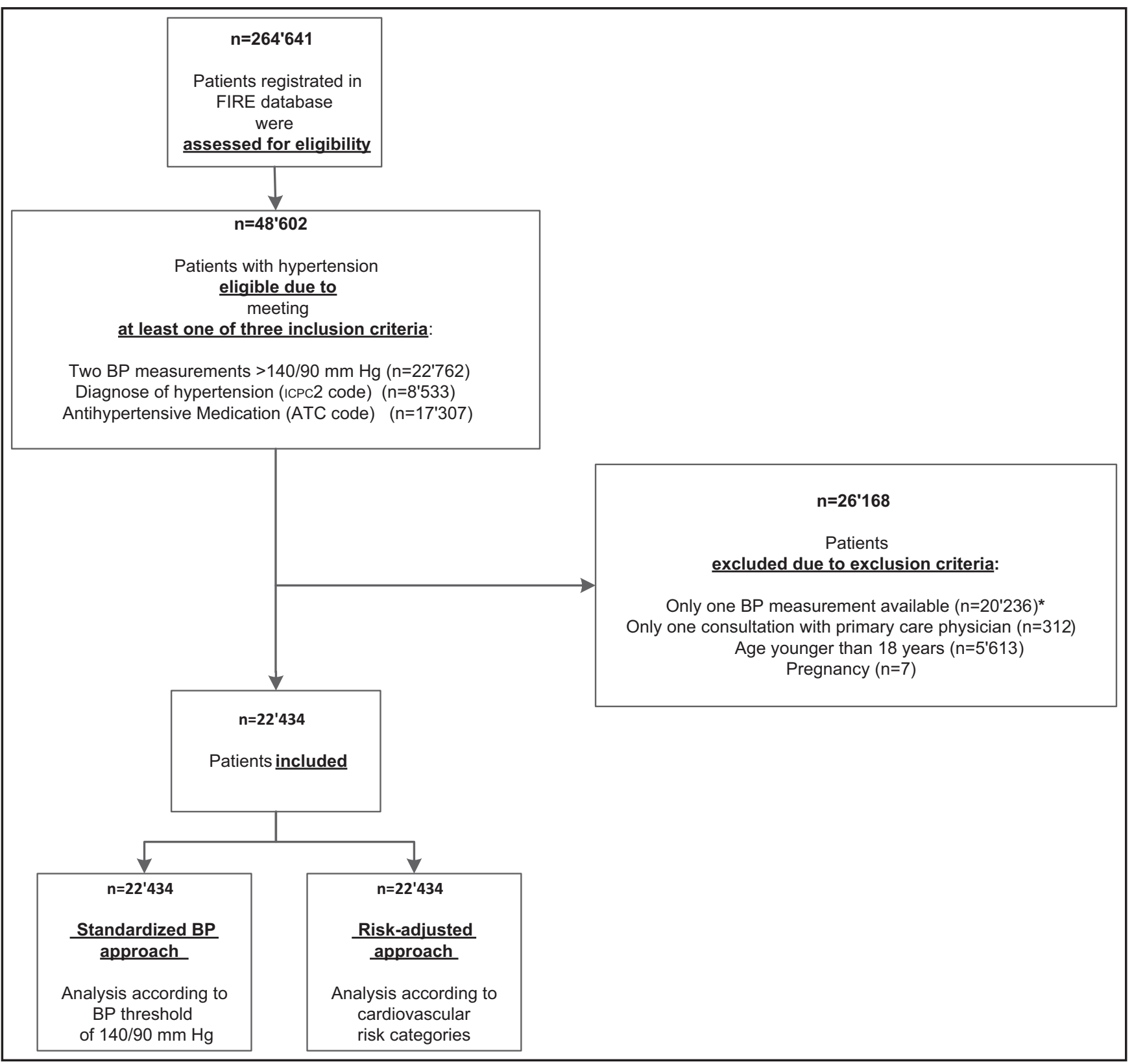

FIGURE 2 Inclusion flowchart. ATC, Anatomical Therapeutic Chemical Classification System; BP, blood pressure; FIRE, Family Medicine ICPC-Research Using Electronic Medical Records; ICPC-2, second version of the International Classification of Primary Care

8.1\% (1816/22 434) were assigned to the "very high" CVR category. Results of stratification of patients to different CVR categories are shown in Figure 1.

The age stratification of all 2416 patients affected by the riskadjusted EPG approach showed that 11.1\% (266/2416) of these patients were 60 years or younger, while $88.9 \%(2150 / 2416)$ were older than 60 years (Figure 4).

Among patients younger than 60 years, three patients were identified as being affected by ISH.

Sensitivity analysis splitting the 6-year observation period into two periods of 3 years each showed no relevant difference in clinical practice concerning our main outcome of "appropriateness of hypertension treatment."

\section{4 | DISCUSSION}

In this study, we applied two different approaches to data of patients with hypertension treated in Swiss primary care to evaluate the proportion of patients who qualify for treatment and are affected by the EPG. That way, we were able to demonstrate the actual impact of individualized risk adjustment compared with assessment based on a rigid $\mathrm{BP}$ threshold.

Using the standardized BP approach, the proportion of patients with hypertension who qualified for drug treatment was $72.7 \%$ compared with $44.6 \%$ using the risk-adjusted approach, resulting in a difference of $28.1 \%$. The proportion of patients identified as being 


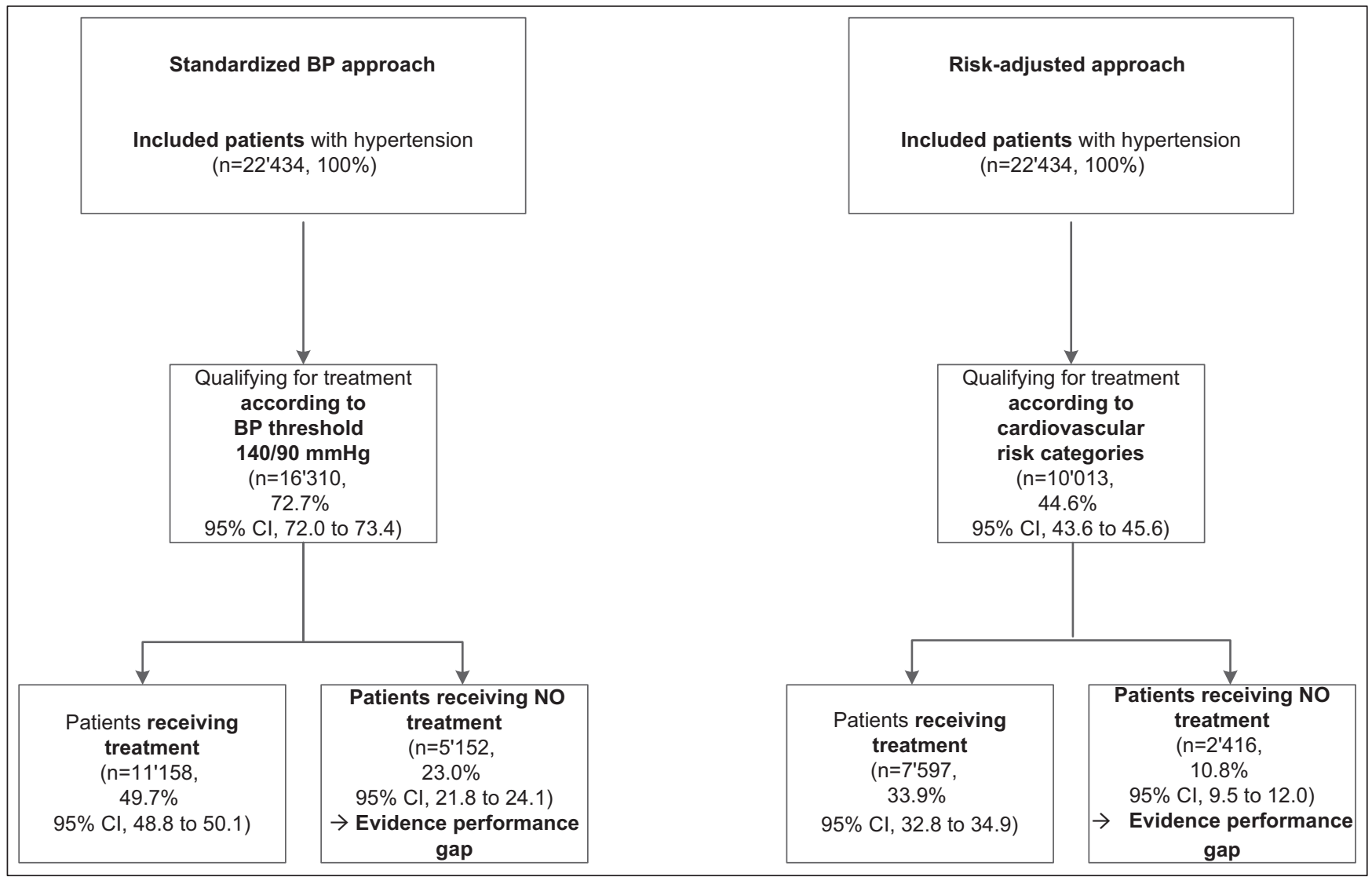

FIGURE 3 Patients with hypertension. BP, blood pressure; $\mathrm{Cl}$, confidence interval

affected by the EPG decreased from $23.0 \%$ using the standardized BP approach to $10.8 \%$ using the risk-adjusted approach, resulting in a difference of $12.2 \%$.

Our results using the standardized BP approach are comparable to previous studies that only used the standardized BP approach and neglected patients' individual CVR factors. Some of these studies described a decrease of the EPG over time but attributed it to reasons such as a healthier lifestyle, increase of drug treatment, or higher awareness of hypertension. ${ }^{10,11,13,14,37,38}$

Scheltens and colleagues ${ }^{12}$ were the first and only authors who used a more individualized approach estimating the EPG in hypertension management based on the Framingham risk function. However, they applied this approach only to a small $(n=292)$ and special subgroup of patients with hypertension who were free from cardiovascular disease and had an average age of 38 years. Moreover, this approach was based on a number of assessment criteria that is currently considered outdated. $^{12}$

Recently, Navar-Boggan and colleagues ${ }^{39}$ demonstrated that the introduction of a new guideline for hypertension management in the United States significantly changed the proportion of patients who qualified for treatment.

Applying the 2013 ESH/ESC guidelines, we are now the first to use a risk-adjusted approach. This risk-adjusted approach reduced the EPG by more than $50 \%$. A more detailed analysis of the proportion of patients (10.8\%) affected by the EPG using the risk-adjusted approach showed that the majority (88.9\%) of patients was older than 60 years when stratified by age. Unfortunately, specifications of terms concerning age such as "elderly" are vague and differ considerably depending on the source. ${ }^{24,32-35,40}$ Therefore, we refrained from using a clear age threshold when assessing appropriateness of treatment. Nevertheless, one should keep in mind that the observed EPG might further decrease depending on the definition of "elderly."

In addition to age, but partially associated with age, there are other factors such as patient frailty, orthostatic hypotension, vertigo, social circumstances, individual compliance, and preferences, as well as comorbidities and preexisting polypharmacy, that might influence the decision process. One faces the challenge of balancing advantages and disadvantages of additional treatment based on these factors. Obviously, additional treatment as well as concomitant chronic disease will complicate the decision. ${ }^{41}$ In this study, patients had a mean of 4.8 concomitant chronic diseases and received 5.9 concomitant drugs. These circumstances emphasize that more effective studies in primary care are needed in order to define the evidence base of treatment, since patients with multimorbid disease with concomitant polypharmacy are often excluded from guideline-influencing randomized controlled trials. For example, one of the latest studies on the topic of BP management excluded patients affected by dementia, diabetes, history of stroke, and those living in a nursing home who are commonly found in the primary care setting. ${ }^{42}$ This study among patients with high CVR targeting an SBP of $<120 \mathrm{~mm} \mathrm{Hg}$, as compared with $<140 \mathrm{~mm} \mathrm{Hg}$, resulted in lower rates of fatal and nonfatal major cardiovascular events and death from any cause, although 
TAB LE 2 Baseline characteristics of included patients

\begin{tabular}{|c|c|c|}
\hline \multirow[b]{2}{*}{ Characteristics } & \multicolumn{2}{|c|}{ Included Patients ( $\mathrm{n}=22$ 434) } \\
\hline & Mean & $\begin{array}{l}\text { Standard } \\
\text { Deviation }\end{array}$ \\
\hline Age, y & 66.4 & 15.6 \\
\hline Observation period, $y$ & 2.7 & 1.9 \\
\hline Antihypertensive drugs ${ }^{\mathrm{a}}$ (number per patient) & 1.8 & 1.0 \\
\hline Concomitant drugs (number per patient) & 5.9 & 5.9 \\
\hline Concomitant chronic diseases (number per patient) & 4.8 & 3.7 \\
\hline Blood pressure measurements (total number per patient) & 9.7 & 12.1 \\
\hline \multirow[t]{2}{*}{ Blood pressure measurements (number per patient per year) } & 3.7 & 6.3 \\
\hline & Number & Percentage \\
\hline \multicolumn{3}{|l|}{ Hypertension grade } \\
\hline Normal (SBP $\leq 129 \mathrm{~mm} \mathrm{Hg}$ or DBP $\leq 84 \mathrm{~mm} \mathrm{Hg}$ ) & 1224 & 5.5 \\
\hline High normal (SBP 130-139 mm Hg or DBP $85-89$ mm Hg) & 4900 & 21.8 \\
\hline Grade 1 (SBP 140-159 mm Hg or DBP 90-99 mm Hg) & 12672 & 56.5 \\
\hline Grade 2 (SBP $160-179$ mm Hg or DBP $100-110$ mm Hg) & 3118 & 13.9 \\
\hline Grade 3 (SBP $\geq 180 \mathrm{~mm} \mathrm{Hg}$ or DBP $\geq 110 \mathrm{~mm} \mathrm{Hg}$ ) & 520 & 2.3 \\
\hline \multicolumn{3}{|l|}{ Risk factors } \\
\hline Male sex & 11364 & 50.7 \\
\hline Age (male $\geq 55$ y; female $\geq 65$ y) & 14143 & 63.0 \\
\hline Dyslipidemia & 1500 & 6.7 \\
\hline Obesity & 5989 & 26.7 \\
\hline Elevated fasting glucose ${ }^{b}$ & 74 & 22.6 \\
\hline \multicolumn{3}{|l|}{ Asymptomatic organ damage } \\
\hline Pulse pressure $\geq 60 \mathrm{~mm} \mathrm{Hg}$ (in patients $\geq 65 \mathrm{y}$ ) & 12736 & 56.8 \\
\hline Chronic kidney disease Grade $3^{c}$ & 2184 & 21.8 \\
\hline \multicolumn{3}{|l|}{ Established disease } \\
\hline Chronic kidney disease Grade $4^{c}$ & 238 & 2.4 \\
\hline Diabetes & 918 & 4.1 \\
\hline Cardiovascular disease & 1041 & 4.6 \\
\hline
\end{tabular}

DBP, diastolic blood pressure; SBP, systolic blood pressure.

${ }^{2}$ Data calculated only among patients with antihypertensive drugs ( $n=13506,60.2 \%$ of 22434 ).

${ }^{b}$ Data calculated only among patients where laboratory data were available ( $n=328,1.5 \%$ of 22434$)$.

${ }^{c}$ Data calculated only among patients where laboratory data were available ( $n=12426,55.4 \%$ of 22434 ).

the intensive-treatment group experienced significantly higher rates of some adverse events. ${ }^{42,43}$ These results, supported by data from a large meta-analysis, will influence future guidelines and stress the importance of risk adjustment and patient-centeredness. ${ }^{44}$

\subsection{Strengths und limitations}

In our dataset, the prevalence of hypertension is seemingly low compared with other studies in the primary care setting., ${ }^{90,14,21,45-47}$ This is explained by exclusion of patients who had fewer than two encounters with their PCP and/or fewer than two BP measurements. This decision was taken because we aimed to specifically analyze PCPs' treatment performance, as it is unlikely that PCPs have an influence on patients' hypertension treatment without regular contact. Leaving these patients within our analysis, the prevalence of patients with hypertension would have been $18.4 \%$, and thus similar to other studies in this setting. Nevertheless, our analysis is still based on data of 22434 patients.

Our data were extracted from routinely collected data from medical records. Therefore, they are subject to the usual limitations of routine data. ${ }^{48,49}$ We assessed patients' CVR profile according to the 2013 ESH/ESC guidelines, but some variables (ie, smoking, abdominal obesity, family history for premature cardiovascular diseases, and indicators for asymptomatic organ damage) were limited or not available in our dataset. However, PCPs base their daily decisions on the same variables as we did when extracting data from their medical records. Thus, these data are the best available proxy to measure the actual medical care situation of primary care patients with hypertension to date. A prospective study in this setting would be a disruption of daily practice and prone to the Hawthorne effect. 


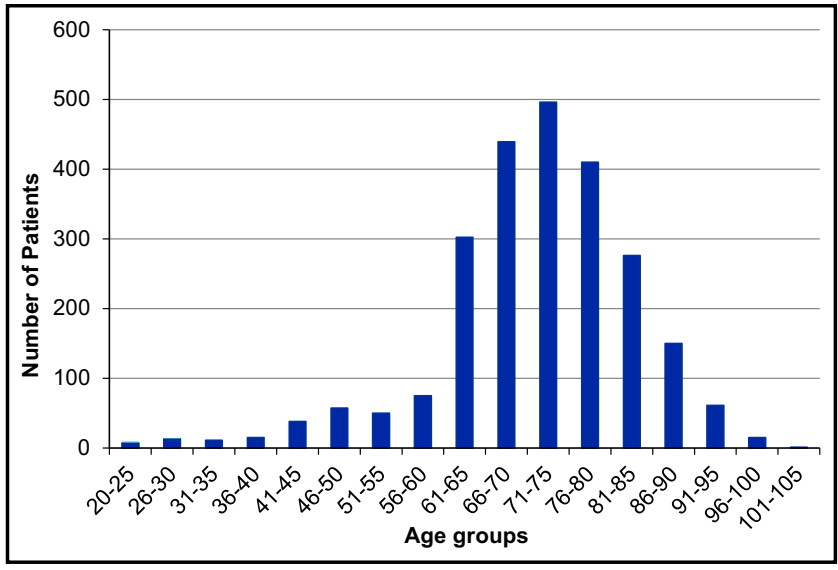

FIGURE 4 Age stratification of patients.

Further, the cross-sectional design of the study may be seen as a limitation, but it has to be acknowledged that data from previous studies is derived from surveys where data collection usually takes place on a single day. In contrast, we evaluated patients who qualified for drug treatment based on the whole available record history.

This study of patients with hypertension in Swiss primary care is of international value because hypertension treatment is an eminent problem in health systems worldwide and the majority of patients with

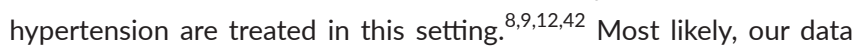
cannot be generalized to other care settings, but countries with an equal health system should take these results as a suggestion to revisit previous EPG estimations. Switzerland serves as a good example of an industrialized country with an insurance-based healthcare system with a fee-for-service reimbursement and mostly free choice of doctors-a model that can also be found in other countries, eg, Austria, France, Germany, and parts of the United States. The estimation of the actual risk-adjusted EPG in Swiss primary care will thus allow an extrapolation of the EPG in these countries.

\section{5 | CONCLUSIONS}

Application of the risk-adjusted approach as recommended by the 2013 ESH/ESC guidelines reduced the EPG by more than $50 \%$. This demonstrates the major impact of risk adjustment and highlights the need for a patient-centered approach in the treatment of hypertension.

\section{ACKNOWLEDGMENT}

We thank the FIRE study group of general practitioners who contributed to the present study.

\section{DISCLOSURES}

The authors report no specific funding in relation to this research and no conflicts of interest to disclose.

\section{REFERENCES}

1. WHO. World Health Organisation. World Health Statistics 2015. http://www.who.int/gho/publications/world_health_statistics/2015/ en/. ISBN 9789240694439 (PDF).

2. Patel SA, Winkel M, Ali MK, Narayan KM, Mehta NK. Cardiovascular mortality associated with 5 leading risk factors: national and state preventable fractions estimated from survey data. Ann Intern Med. 2015;163:245-253.

3. Kearney PM, Whelton M, Reynolds K, Muntner P, Whelton PK, He J. Global burden of hypertension: analysis of worldwide data. Lancet. 2005;365:217-223.

4. Mancia G, Fagard R, Narkiewicz K, et al. 2013 ESH/ESC guidelines for the management of arterial hypertension: the Task Force for the Management of Arterial Hypertension of the European Society of Hypertension (ESH) and of the European Society of Cardiology (ESC). Eur Heart J. 2013;34:2159-2219.

5. Law MR, Morris JK, Wald NJ. Use of blood pressure lowering drugs in the prevention of cardiovascular disease: meta-analysis of 147 randomised trials in the context of expectations from prospective epidemiological studies. BMJ. 2009;338:b1665.

6. NICE. National Institute for health and Care Excellence. Hypertension in adults: diagnosis and management (CG127). Clinical guideline Published: 24 August 2011 nice.org.uk/guidance/cg127.

7. James PA, Oparil S, Carter BL, et al. 2014 evidence-based guideline for the management of high blood pressure in adults: report from the panel members appointed to the Eighth Joint National Committee (JNC 8). JAMA. 2014;311:507-520.

8. Borghi C, Dormi A, D'Addato S, Gaddi A, Ambrosioni E, Brisighella Heart Study Working Party. Trends in blood pressure control and antihypertensive treatment in clinical practice: the Brisighella Heart Study. J Hypertens. 2004;22:1707-1716.

9. Chow CK, Teo KK, Rangarajan S, et al. Prevalence, awareness, treatment, and control of hypertension in rural and urban communities in high-, middle-, and low-income countries. JAMA. 2013;310: 959-968.

10. Egan BM, Zhao $\mathrm{Y}$, Axon RN. US trends in prevalence, awareness, treatment, and control of hypertension, 1988-2008. JAMA. 2010;303:2043-2050.

11. Wilkins K, Campbell NR, Joffres MR, et al. Blood pressure in Canadian adults. Health Rep. 2010;21:37-46.

12. Scheltens $T$, Bots ML, Numans ME, Grobbee DE, Hoes AW. Awareness, treatment and control of hypertension: the 'rule of halves' in an era of risk-based treatment of hypertension. J Hum Hypertens. 2007;21:99-106.

13. Sarganas G, Neuhauser HK. Untreated, uncontrolled, and apparent resistant hypertension: results of the German Health Examination Survey 2008-2011. J Clin Hypertens (Greenwich). 2016;18:1146-1154.

14. Joffres $M$, Falaschetti E, Gillespie $C$, et al. Hypertension prevalence, awareness, treatment and control in national surveys from England, the USA and Canada, and correlation with stroke and ischaemic heart disease mortality: a cross-sectional study. BMJ Open. 2013;3:e003423.

15. Dechend R, Kaiser E, Derer W, et al. Guideline adherence in cardiovascular risk assessment and analysis in 15,000 hypertensive German patients in real life: results of the Prospective 3A Registry. J Clin Hypertens (Greenwich). 2012;14:496-501.

16. Djalali S. Evidence-performance gap in primary care revisited in patients with diabetes. Exp Clin Cardiol. 2014;20:1655-1664.

17. Markun S, Dishy A, Neuner-Jehle S, Rosemann T, Frei A. The chronic care for wet age related macular degeneration (CHARMED) study: a randomized controlled trial. PLOS ONE. 2015;10:e0143085.

18. Boeckxstaens P, Peersman W, Goubin G, et al. A practice-based analysis of combinations of diseases in patients aged 65 or older in primary care. BMC Fam Pract. 2014;15:159. 
19. Afshar S, Roderick PJ, Kowal P, Dimitrov BD, Hill AG. Multimorbidity and the inequalities of global ageing: a cross-sectional study of 28 countries using the World Health Surveys. BMC Public Health. 2015;15:776.

20. Patel S, Kai J, Atha C, et al. Clinical characteristics of persistent frequent attenders in primary care: case-control study. Fam Pract. 2015;32:624-630.

21. Zellweger U, Bopp M, Holzer BM, Djalali S, Kaplan V. Prevalence of chronic medical conditions in Switzerland: exploring estimates validity by comparing complementary data sources. BMC Public Health. 2014;14:1157.

22. Djalali S, Senn O. Trends in family medicine - how to sort the wheat from the chaff. Praxis. 2015;104:1251-1258.

23. Heneghan C, Perera R, Mant D, Glasziou P. Hypertension guideline recommendations in general practice: awareness, agreement, adoption, and adherence. Br J Gen Pract. 2007;57:948-952.

24. Mancia G, Fagard R, Narkiewicz K, et al. 2013 ESH/ESC guidelines for the management of arterial hypertension. J Hypertens. 2013;31:1281-1357.

25. Verbeke M, Schrans D, Deroose S, et al. The International Classification of Primary Care (ICPC-2): an essential tool in the EPR of the GP. Stud Health Technol Inform. 2006;124:809-814.

26. WONCA. World Organization of National Colleges, Academies and Academic Associations of General Practitioners/Family Physicians: ICPC-2-R: International Classification of Primary Care. Oxford: Oxford University Press; 2005.

27. WHO. World Health Organisation. Collaborating Centre for Drug Statistics Methodology, Guidelines for ATC classification and DDD assignment 2013. Oslo, 2012. https://www.whocc.no/filearchive/publications/1_2013guidelines.pdf. ISBN 978-82-8082-525-4.

28. Chmiel C, Bhend H, Senn O, Zoller M, Rosemann T, FIRE StudyGroup. The FIRE project: a milestone for research in primary care in Switzerland. Swiss Med Wkly. 2011;140:w13142.

29. Lamers LM, van Vliet RC. The Pharmacy-based Cost Group model: validating and adjusting the classification of medications for chronic conditions to the Dutch situation. Health Policy. 2004;68:113-121.

30. O'Halloran J, Miller GC, Britt H. Defining chronic conditions for primary care with ICPC-2. Fam Pract. 2004;21:381-386.

31. O'Rourke MF, Adji A. Guidelines on guidelines: focus on isolated systolic hypertension in youth. J Hypertens. 2013;31:649-654.

32. Mancia G, Fagard R, Narkiewicz K, et al. 2013 ESH/ESC practice guidelines for the management of arterial hypertension. Blood Press. 2014;23:3-16.

33. WHO. Programmes: Health Statistics and Information Systems: Definition of an Older or Elderly Person. World Health Organization. http:// www.who.int/healthinfo/survey/ageingdefnolder/en/\#. Accessed November 26, 2015.

34. Aronow WS, Fleg JL, Pepine CJ, et al. ACCF/AHA 2011 expert consensus document on hypertension in the elderly: a report of the American College of Cardiology Foundation Task Force on Clinical Expert Consensus Documents developed in collaboration with the American Academy of Neurology, American Geriatrics Society, American Society for Preventive Cardiology, American Society of Hypertension, American Society of Nephrology, Association of Black Cardiologists, and European Society of Hypertension. J Am Soc Hypertens. 2011;5:259-352.

35. Hansson L, Lithell H, Skoog I, et al. Study on COgnition and Prognosis in the Elderly (SCOPE). Blood Press. 1999;8:177-183.
36. Tobi $\mathrm{H}$, van den Berg PB, de Jong-van den Berg LT. Small proportions: what to report for confidence intervals? Pharmacoepidemiol Drug Saf. 2005;14:239-247.

37. Bromfield SG, Bowling CB, Tanner RM, et al. Trends in hypertension prevalence, awareness, treatment, and control among US adults 80 years and older, 1988-2010. J Clin Hypertens (Greenwich). 2014;16:270-276.

38. Tocci G, Muiesan ML, Parati G, et al. Trends in prevalence, awareness, treatment, and control of blood pressure recorded from 2004 to 2014 during world hypertension day in Italy. J Clin Hypertens (Greenwich). 2016;18:551-556.

39. Navar-Boggan AM, Pencina MJ, Williams K, Sniderman AD, Peterson ED. Proportion of US adults potentially affected by the 2014 hypertension guideline. JAMA. 2014;311:1424-1429.

40. Probstfield JL, Applegate WB, Borhani NO, et al. The Systolic Hypertension in the Elderly Program (SHEP): an intervention trial on isolated systolic hypertension. SHEP Cooperative Research Group. Clin Exp Hypertens A. 1989;11:973-989.

41. Luijks $\mathrm{H}$, Biermans $\mathrm{M}$, Bor $\mathrm{H}$, et al. The effect of comorbidity on glycemic control and systolic blood pressure in type 2 diabetes: a Cohort study with 5 year follow-up in primary care. PLoS ONE. 2015;10:e0138662.

42. Wright JT Jr, Williamson JD, Whelton PK, et al. A randomized trial of intensive versus standard blood-pressure control. N Eng J Med. 2015;373:2103-2116.

43. Ettehad D, Emdin CA, Kiran A, et al. Blood pressure lowering for prevention of cardiovascular disease and death: a systematic review and meta-analysis. Lancet. 2015;387:957-967.

44. Brenk-Franz K, Strauss B, Tiesler F, et al. The influence of adult attachment on patient self-management in primary care--the need for a personalized approach and patient-centred care. PLOS ONE. 2015;10:e0136723.

45. Guessous I, Bochud M, Theler JM, Gaspoz JM, Pechere-Bertschi A. 1999-2009 Trends in prevalence, unawareness, treatment and control of hypertension in Geneva, Switzerland. PLoS ONE. 2012;7:e39877.

46. Neuhauser HK, Adler C, Rosario AS, Diederichs C, Ellert U. Hypertension prevalence, awareness, treatment and control in Germany 1998 and 2008-11. J Hum Hypertens. 2014;29:247-253.

47. Bramlage $P$, Thoenes $M$, Kirch $W$, Lenfant $C$. Clinical practice and recent recommendations in hypertension management - reporting a gap in a global survey of 1259 primary care physicians in 17 countries. Curr Med Res Opin. 2007;23:783-791.

48. Grobbee D, Hoes A, Verheij TM, Schrijvers AP, Ameijden ECV, Numans $M$. The Utrecht Health Project: optimization of routine healthcare data for research. Eur J Epidemiol. 2005;20:285-290.

49. Smeets HM, de Wit NJ, Hoes AW. Routine health insurance data for scientific research: potential and limitations of the Agis Health Database. J Clin Epidemiol. 2011;64:424-430.

How to cite this article: Zechmann S, Senn O, Valeri F, Neuner-Jehle S, Rosemann T, and Djalali S the FIRE Study Group. The impact of an individualized risk-adjusted approach on hypertension treatment in primary care. J Clin Hypertens, 2017;00:1-9. doi:10.1111/jch.12958 


\section{Verdankung und Widmung}

Ich möchte mich bei allen Mitarbeitern des Institutes für Hausarztmedizin Zürich, insbesondere Dr. med. Sima Djalali, Dr. med. Stefan Neuner-Jehle MPH, Fabio Valeri, Prof. Dr. med. Oliver Senn MPH, und Prof. Dr. med. Thomas Rosemann PhD bedanken.

Ein grosses Dankeschön meiner Familie, allen voran meinem Schatz Nadja.

Ich möchte diese Arbeit meinem Grossvater Dr. Rolf Ramsauer widmen, welcher den Abschluss dieser Arbeit leider nicht mehr erleben durfte. 


\section{Curriculum Vitae}

\section{Zechmann Stefan}

06.04.1982

$1988-1992$

$1993-2000$

1998 - 1999

$06 / 2000$

$2000-2001$

$2001-2008$
Geboren in Klagenfurt, Kärnten, Österreich

Volkschule Lind, Villach, Österreich

Bundesrealgymnasium Perau, Villach, Österreich

Schüleraustausch mit AFS in Neuseeland

Matura, Villach, Österreich

Militärdienst, Einjährig-Freiwillig, Österreich

Studium Humanmedizinstudium an der medizinischen Fakultät

der Karl-Franzens Universität Graz, Graz. Aufgrund einer

Neugründung Abschluss an der Medizinische Universität Graz,

Graz

21.04.2008

$12 / 2008-06 / 2009$

Studienabschluss: Verleihung des akademischen Grades

Doktor der gesamten Heilkunde (Dr. med. univ.)

10/2009 - 04/2010 Lehrpraxis MD Dr. Frischauf, Österreich, Turnusarzt

05/2010 - 06/2011 Bezirkskrankenhaus St. Johann in Tirol, Österreich, Turnusarzt

06/2011 - 08/2011 Expeditionsarzt einer OEAV-Expedition zum G1- G2 - K2

Pakistan

09/2011 - 09/2013 Kantonspital Baden, Baden, Assistenzarzt Innere Medizin

10/2013 - 12/2014 UniversitätsSpital Zürich, Zürich, Assistenzarzt Innere Medizin

01/2015 - aktuell UniversitätsSpital Zürich, Zürich, Institut für Hausarztmedizin, Wissenschaftlicher Mitarbeiter

10/2015 - aktuell Praxis Dr. Villiger, Dättwil/Baden, Praxistätigkeit Facharzt Allgemeine Innere Medizin, Assistenzarzt für Diabetologie und Endokrinologie 